\title{
INTEGRATED USE OF GIS, REMOTE SENSING DATA AND A SET OF MODELS FOR OPERATIONAL FLOOD FORECASTING
}

\author{
V.A. Zelentsov, S.A. Potryasaev, I.Yu. Pimanov*, M.R. Ponomarenko
}

St. Petersburg Institute for Informatics and Automation of the Russian Academy of Sciences (SPIIRAS), St. Petersburg, Russia v.a.zelentsov@gmail.com, spotryasaev@gmail.com, pimen@list.ru,pnmry@yandex.ru

KEY WORDS: Floods, Operational Forecasting, Integrated Modeling, Service-oriented Architecture, Hydrodynamic Models, Geoinformation Systems, Remote Sensing Data

\begin{abstract}
:
The research is aimed at the development and testing of the system for operational river flood forecasting. The system is based on the use of a complex of hydrological and hydrodynamic models, as well as in situ and satellite data integrated processing, and implemented on the basis of a service-oriented architecture. A distinctive feature of the system is the complete automation of the entire simulation cycle - from loading initial data to interpreting results, visualizing and alerting interested parties. The theoretical basis for ensuring the coordinated functioning of all system components is the qualimetry of models and polymodel complexes. The practical implementation is carried out using open codes, free software and GIS platform «RegionView».

All the complexity associated with the use of heterogeneous geographically distributed information resources is hidden from the user. This allows the system to be used not only by specialists in GIS, IT or relevant subject area, but also by other users interested in the results of flood monitoring and forecasting - emergency services, local authorities, commercial organizations and citizens.

The described technologies and the system of operational flood forecasting were tested in the Russian Federation on the Northern Dvina River, from the city of Velikiy Ustyug to the city of Kotlas in 2014-2019.

Given test results prove that the application of such an approach ensures full implementation of the required functionality of operational flood forecasting systems, the fulfilment of the basic requirements for such systems and also indicate the possibility of a widespread use of such systems authorities and emergency services.
\end{abstract}

\section{INTRODUCTION}

The research in the field of creating systems for operational flood forecasting is currently very relevant. The frequency of these emergencies remain high which leads to severe consequences and significant economic losses. At the same time, there is still a lack of applications that can provide decision makers with the most reliable information about the dynamics of emergencies promptly and in a simple visual form. Describing the state-of-the-art of the problem regarding the development of operational flood forecasting technologies it is necessary to note at least the following important factors:

- current information systems and services for flood monitoring and forecasting;

- remote sensing data application;

- integration of heterogeneous information resources.

Current information systems and services for flood monitoring and forecasting. Currently, the international community is actively developing information systems and services for solving problems of flood monitoring and forecasting. The functionality of such hydrodynamic models as Mike FLOOD (Danish Hydrological Institute, 2019), Delft 3D (Deltares, Delft3D Development Team, 2019), HEC-RAS (Hydrologic Engineering Center, 2019), LISFLOOD (University of Bristol, 2019) and others is improving. The most well-known information systems using mathematical models include: Flood Early Warning Systems (FEWS) (Deltares, 2019), North American National Water Model (NWM) (NOAA National Water Center, 2019), European Flood Awareness System (Copernicus Emergency Management Service, EFAS, 2019), based on the LISFLOOD model, and some others. These systems are focused on the territories of North American and European countries and have a well-developed network of stations and observation posts - sources of hydrological and meteorological data. To forecast situations on Russian rivers, it is necessary to take into account such features as sparseness of hydrometeorological observations network, the occurrence of ice jams, the absence of highly detailed digital elevation and terrain models for potentially dangerous river valleys, etc.

Recently, a number of new services, based on the use of remote sensing data, have been developed:

- Copernicus Emergency Management Service, which includes Mapping service (Copernicus Emergency Management Service, Mapping, 2019) and Global Flood Awareness System (Copernicus Emergency Management Service, GloFAS, 2019);

- Thematic Exploitation Platform - Hydrology (TEP Hydrology) (European Space Agency, 2019), which includes the Flood Monitoring Service.

However, as before, the existing services do not involve the use of mathematical models that most adequately take into account the features of the Russian rivers and are intended mainly for the flow monitoring and forecasting tasks, and not for operational forecasting of river floods.

To calculate flooded areas and water flow movement of Russian rivers, the most widespread hydrodynamic models are STREAM_2D models (Aleksyuk A.I., Belikov V.V., 2017). Despite the good testing results on a number of the Russian territories, they can now be used mainly by hydrologists or for solving particular modeling problems due to insufficient development of such issues as the automation of obtaining and processing of source data, locality of execution, and other information technology constraints. There are examples of 
projects that implement mathematical predictive models of river hydrological regime during floods and certain cases of automated and automatic systems application for collecting hydrological information (Borsch et al., 2015). However, software developers have often relied on the use of fairly complex proprietary software (ArcGIS, etc.) or certain information exchange standards (Bugayets et al., 2015), which leads to strong limitations on the scaling of obtained solutions. Freely distributed flood modeling software is represented only by a number of applications by the American Corps of Military Engineers (HEC-RAS, HEC-GeoRAS, HEC-HMS, HECGeoHMS). Free closed source solutions (for example, Flood Modeller (Jacobs, 2019)) have strict limitations on the functionality and dimension of the processed data.

Remote sensing data application. Today remote sensing data is one of the main sources of information about the actual boundaries of rivers and flooded areas zones. This data is becoming more accessible and convenient to use. The European Space Agency is taking great practical steps in this direction, developing technologies for the operational use of data from Sentinel satellites. The quality of data from the Russian satellites "Kanopus-V" and "Resurs-P" (which are actively used by the Emercom services of Russia) is also being improved, with their increased use for solving flood monitoring tasks. Within the framework of international agreements, in particular, the International Charter on Space and Major Disasters, it is possible to use the resource of operational satellite imagery of all participants in the charter (15 organizations, including national and international space agencies) in case of an emergency. In addition, the rapid development of unmanned aerial vehicles (UAVs), related imaging equipment and software tools for processing UAV images also expand the set of input data to improve the accuracy of flood modeling and forecasting. There are a number of works (Ponomarenko M. R., Pimanov I. Y., 2017; Refice A., D'Addabbo A., Capolongo D., 2017) on automating the detection of flooded areas on the basis of remote sensing data and ground data. However, the questions of using this source of information in complex systems for flood modeling remain open.

Integration of heterogeneous information resources. Today information technologies for integrating heterogeneous information resources are increasingly based on the use of open source software, including geographic information systems (GIS) that are an integral component of flood forecasting systems (CARTO, NextGIS, MapBox, Urbica). Modern technologies in this field make it possible to create simplified means of user interaction with complex systems (Zelentsov V.A., Potryasaev S.A., 2017). However to date there are not enough examples of using information technologies and software to fully automate the entire cycle of flood modeling from gathering and processing ground and aerospace data to publishing the results and notifying interested persons and organizations.

In general, the analysis of existing developments of operational flood forecasting systems shows that there is still a gap between 3 categories of specialists:

- the developers of hydrological and hydrodynamic models;

- the developers of information technologies and software tools for processing heterogeneous data;

- practitioners who are still unable to quickly use the results of mathematical modeling due to insufficient automation of forecast systems and the absence of convenient and simple means for interaction with modeling complexes.

To bridge this gap and provide highly accurate assessment of flood boundaries and water levels (taking into account the specific conditions of water flow distribution), the authors proposed an approach to creating intelligent information systems for operational forecasting of river floods based on the use of a complex of hydrological and hydrodynamic models (Alabyan A. M. et al., 2016; Zelentsov V.A. et al., 2016). The principal features of this approach are the following:

- the integrated use of ground and aerospace data for modeling; - selection and application of approved mathematical models describing the catchment and water flow;

- full automation of all stages of modeling - from collecting and loading source data to analyzing potential damage and alerting interested parties.

According to the proposed approach, the operational short-term (12-48 hours ahead) forecasting system with integrated use of GIS, remote sensing data and a set of models was developed. The article presents the most important aspects of system implementation and the results of its testing.

\section{GENERAL STRUCTURE OF THE INTEGRATED SYSTEM}

The proposed automated flood forecasting technology is based on the concept of a multi-model description of complex natural objects. This concept includes a mechanism for selection and adaptation (structural and parametric) of the most adequate model for each specific situation (Alabyan A. M. et al., 2016; Sokolov B.V. et al., 2015). The concept is currently being developed within the framework of qualimetry of models and polymodel complexes which is a new scientific field.

According to this concept, there is no universal model of flooding in different parts of the river, varied by length and configurations. When choosing hydrodynamic models, it is advisable to implement a multi-model approach. Depending on the river valley length and data availability, it is possible to choose between 2 types of models:

- one-dimensional hydrodynamic models for long river valleys $(100-1000 \mathrm{~km})$;

- two-dimensional models for river valleys less than $100 \mathrm{~km}$ in length with a significant width floodplains, their complex configuration, the location of various structures in floodplains (Alabyan A. M. et al., 2016).

Experience shows that it is efficient to study and monitor long river objects through joint (hybrid, integrated, multi-scale) calculation by one-dimensional and two-dimensional models.

The general architecture of developed model-oriented operational flood forecasting system is shown in Fig. 1. The system was built with the use of a service-oriented architecture (SOA) (Zelentsov V.A., Potryasaev S.A., 2017; Paik H. et al., 2017) that provides flexible interaction between software modules, implementing subject area models (in this research hydrodynamic and hydrological models); modules of heterogeneous data collecting and processing (including data from gauging stations and remote sensing data); control modules, etc. In this case, all system components are implemented as web services and can be geographically distributed and localized in various organizations, cities and countries.

The most important issue in the SOA implementation is the way of connecting disparate modules and organization of their interaction during system operation. The SOA does not imply any way of organizing the information flow between a multitude of services, apart from connecting applications on a point-topoint basis. Such interaction leads to the problem of a rapid increase in system complexity when adding new participants. Instead, it is advisable to create an infrastructure for information 
exchange in a way that third-party software systems are connected in the form of modules to a universal control application that organizes computational processes for solving consumer applied problems, and the information exchange itself is based on the principles of event-oriented architecture.

Event-oriented approach in distributed information systems can practically be implemented as an Enterprise Service Bus (He W., Xu L.D., 2014). It provides centralized and unified eventoriented messaging between the various components of an information system. Messaging between different systems occurs through a single point, which provides transactional control, data conversion, message auditing. In case of changing any system component connected to the service bus, there is no need to reconfigure other subsystems.
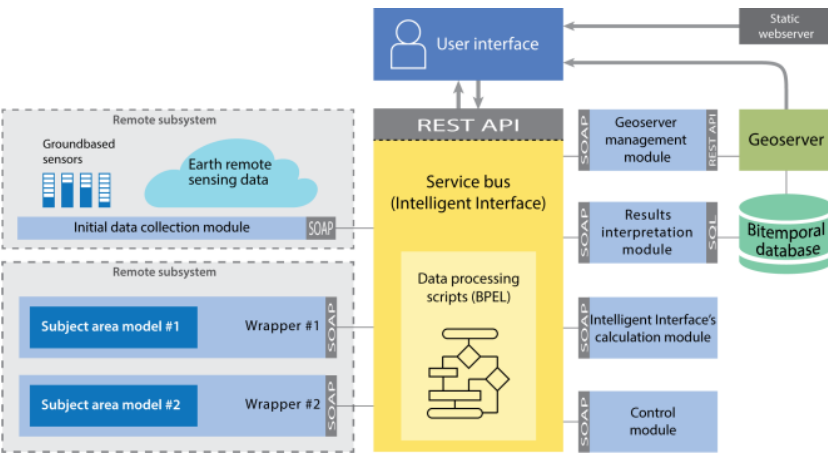

Figure 1. Generalized scheme of the information system for operational flood forecasting

The concept of the service bus provides the possibility of organizing the synthesis of computational processes, but does not directly declare the way to realize this possibility. To describe the automatic management of a set of services, the term "web services orchestration" is used in literature (Wang Y., 2016). Orchestration describes how services should interact with each other using messaging, including business logic and workflow. In a service-oriented architecture, service orchestration is implemented according to the Business Process Execution Language (WS-BPEL) standard (Ting-Huan K., ChiHua C., Hsu-Yang K., 2016). Over the past decade, WS-BPEL has established itself as an effective language for describing the logic of work of applications based on distributed web services. The use of this language allows one to organize the logic of interaction between modules and web services when solving each specific application task, including the use of a visual editor. This ensures a visual designing of data processing algorithms involving the use of various sources and services. Approaches to creating most of the considered information technology solutions are based on the results presented in the previous research (Alabyan A. M. et al., 2016). The proposed and implemented system includes the following original architectural and software solutions for the automation of operational flood forecasting:

- service bus, represented by the software product OpenESB;

- BPEL script interpreter embedded in the OpenESB service bus;

- software for displaying data according to the standards of web-mapping GeoServer;

- PostgreSQL spatial database management system with PostGIS add-on;

- Python-based administration server;

- data collection service from hydrological sensors;
- service for receiving, processing and downloading remote sensing data;

- service for forecasting the values of hydrodynamic processes parameters;

- service for controlling the work of the calculated hydrodynamic model;

- service for forecasting the level and flow of water at gauging stations;

- service for processing and interpreting the results of calculations;

- user web interface - web application adapted for work on stationary and mobile user terminals.

The operational flood forecasting system was developed with the use of open codes, free software and GIS platform «RegionView» (Zelentsov V.A., Kovalev A.P., Pimanov I.Yu., 2016).

All system data is stored in a bitemporal database. It is based on the temporal data model (TDM), which allows storing information about the data life cycle. TDM is used to store both source data (hydrometeorological) and simulation results. Bitemporality means storing both the time of the relevance of certain data and the transactional time (the moment data is added to the storage). The use of the bitemporal database ensures the operational work of the flood monitoring system and its operation in the mode of historical and scenario modeling.

User access to temporal data is implemented as a time slider in the web interface. The user can view various data (source, historical, and forecast) without special knowledge (for example, a formal query language) simply by moving the time slider (Fig. 2.).
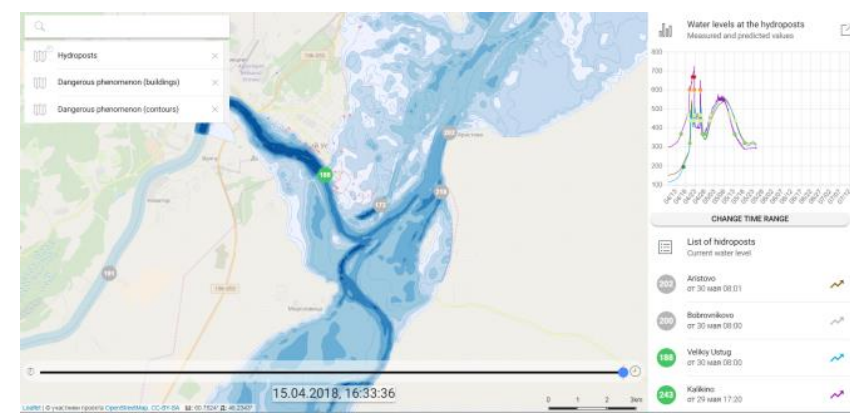

Figure 2. System web interface with a time slider

The developed operational flood forecasting system automatically performs full simulation cycle: from the gathering the source data from hydrological sensors to updating the forecast results in the user interface. As a result of the system work, records are formed in the spatial database, which are converted by the geoserver into the WMS format and delivered to the user interface. The interface provides the end user with the necessary minimum of tools for working with forecasting results: search string of spatial data, list of currently displayed data and time slider for working with temporal data. Thus, all the complexity associated with the use of heterogeneous geographically distributed information systems is hidden from the user due to the full automation of the computational process. This allows the system to be used not only by specialists with a high level of knowledge in the field of GIS and information technology, but also by specialists in the subject area (hydrology) and all other users interested in the results of flood 
forecasting (emergency services, executive authorities, commercial organizations and citizens).

To prepare initial data (water levels and expenditures in predetermined sections of the river) for loading directly into hydrodynamic models the special service was developed. This service is based on a multi-model approach and the concept of choosing mathematical model that most adequately describes and forecasts the hydrological situation for a specific time interval. The alternative models applied for the calculation of water flow are:

- analytical-imitation hydrological models of runoff formation

- models of direct calculation using artificial neural networks (ANN).

The choice of a specific model is determined by the specific conditions of the flood.

\section{REMOTE SENSING DATA PROCESSING}

An important distinctive feature of developed system is the active use of radar (SAR) and optical satellite imagery. Optical data is a valuable source of information for detecting flooding as water surfaces are usually characterized by low spectral brightness values in comparison with surrounding objects and are the darkest areas in optical images. An effective way to automatically detect water bodies using optical data is to calculate indices for estimating the intensity of reflected radiation in various spectral channels. The indices most commonly used for detecting water surfaces include the Normalized Difference Water Index (NDWI) and the Normalized Difference Vegetation Index (NDVI) (Refice A., D'Addabbo A., Capolongo D., 2017).

In case of clouds, which often occur during the hydrological phenomena, the use of radar data significantly expands the capabilities of flood forecasting systems to obtain near real-time information about river ice, current flooded areas and to correct hydrodynamic models parameters (if necessary). The water surfaces on the radar images are usually represented by pixels with a low intensity value due to specular reflection of the radar signal. Today, the automatic detection of water surfaces on SAR data is based on threshold processing, texture analysis, interferometric and polarimetric processing (Refice A., D'Addabbo A., Capolongo D., 2017). The main method is thresholding when during processing all pixels of the image, whose value is less than the set threshold, are assigned to the class of water objects (Chini M. et al., 2017). The accuracy of object recognition depends on the nature of the water surface and is largely determined by the parameters of the source data, in particular, the polarization of the signal at which the images were taken. Most preferred for flood mapping is horizontal $(\mathrm{HH})$ polarization. Cross polarizations $(\mathrm{HV}, \mathrm{VH})$ and their combined use are effective for studying partially flooded areas, as they allow selecting different objects of the terrain (Martinis S., Rieke C., 2015). At the same time, the use of radar data has its limitations: for instance, due to the specifics of SAR sensing geometry, flooding in urban areas may get into the zone of the radar shadow. An effective solution to this problem is a joint analysis of optical and radar data.

The developed system includes an original remote sensing data processing method based on:

- threshold processing of SAR images;

- the calculation of the NDWI index using optical data;

- joint analysis of obtained results.

The use of this approach made it possible to avoid inaccuracies associated with clouds, and at the same time obtain data on flooded areas in urban areas. The results obtained solves a problem of automatic optical and radar data processing to identify flooded areas, and visual comparison of real and simulated contours of flooded areas. Moreover, its implementation as a separate web service allows automating the adjustment procedures of forecast models.

\section{CASE STUDIES}

The described technologies and developed system were tested in 2014-2018 on the Northern Dvina River, from the city of Velikiy Ustyug to the city of Kotlas, Russian Federation. The research area was chosen due to the high frequency of floods with large economic losses. In addition, this area has been studied by hydrologists and was a platform for testing hydrodynamic models (Belikov V.V., et al., 2015; Alabyan A.M., Lebedeva S.V., 2018). Experimental studies were conducted on historical data for the period from 1998 to 2017. In the spring of 2018, testing was carried out in real time mode presenting the results to EMERCOM of Russia and local authorities.

In experiments the model STREAM 2D was used as a hydrodynamic module. It was tested and showed good results on a number of Russian rivers. This model was previously used for scenario calculations in the key area (for evaluating various options for flood control measures, including protective dams). It showed high efficiency in reproducing maximum water levels and flooded areas:

- the difference between the maximum simulated levels and observed levels at flood peaks for the historical period from 1975 to 2013 did not exceed $30 \mathrm{~cm}$;

- the areas of flooding differed by no more than $10 \%$ (Belikov V.V., et al., 2015; Agafonova S.A. et al., 2017).

Water flow formation model ECOMAG (Motovilov Yu., 2013) and ANN were applied to calculate the flow rates entering the hydrodynamic model. ECOMAG was previously successfully employed for scenario calculations of the current runoff and its dynamics during the climate changes in Northern Dvina area (Krylenko I., 2015). During the development of the described forecasting system STREAM 2D and ECOMAG models were used in the operational mode.

During real-time testing, the hydrological data entered the system from 12 fixed and 5 temporary gauging stations (some of them, located in the considered area of flooding simulation, are shown in Fig. 3).

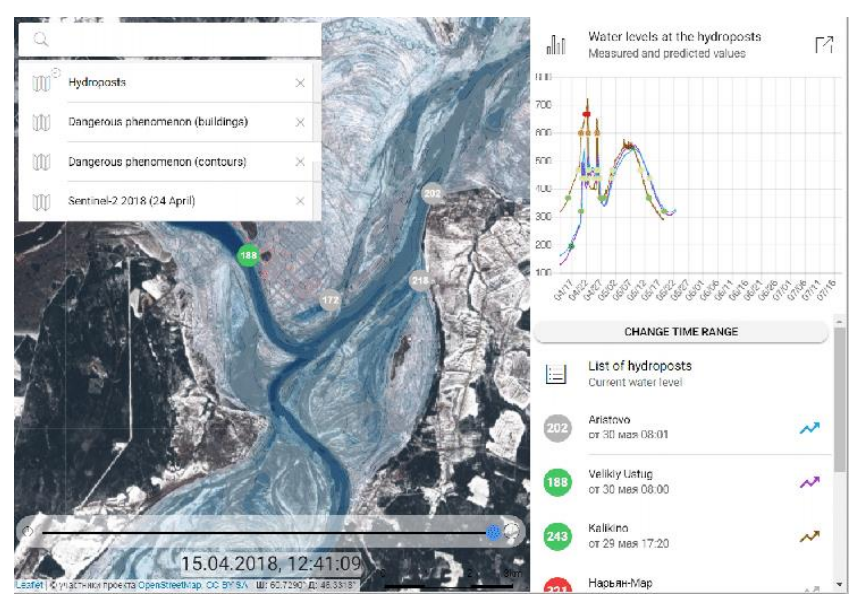

Figure 3. Part of flood modeling area on the Northern Dvina River 
The results of the comparison of ANN and simulation modeling (ECOMAG) shows that the simulation model responded to changes in flood situation much more slowly. However, it more correctly responded to abnormal situations and more accurately determined the trends in the development of such situations in the long term because this type of models takes into account the processes of runoff formation for the entire period, starting from the autumn freezing, snow accumulation, snowmelt, etc. throughout the whole catchment area.

Thus, it can be concluded that ANNs give the best result in the mode of "ordinary" ice drift and are able to forecast with high accuracy long-lasting and inertial changes affecting the water level. This is due to a large set of test cases during the period of normal ice drift, which made it possible to train the ANN with high accuracy to forecast the water level in such conditions. In turn, the forecast of abrupt changes in ice or meteorological situations gives a higher error, since there is not enough training data that would allow considering the level changes in all possible abnormal situations. On the other hand, the occurrence of such situations is due to the reasons arising during the period of freezing of the river or in the winter period. The ANN in its forecast uses only operational data on the current state of the river and, with limited training samples, and is not able to take into account these long-term causes and assess their impact on the water level. The ECOMAG model, in turn, can constructively consider all these data and ensure the forecasting of possible long-term anomalous situations. However, to verify the results obtained by the ECOMAG model in the on-line mode, further development of the forecast adjustment block, based on a comparison of calculated and observed water discharge, is needed.

The results of this part of the experimental studies confirmed the need for the integrated use of various models to improve the accuracy of water levels forecasting required for subsequent calculations of flooded areas and their depths. Therefore, in the process of the system operation, during a normal ice drift, the forecast was made using the ANN. At the same time, during an abnormal situation caused by ice jams, when data on water levels from hydrological posts did not reflect the actual amount of water in the river, switching to a simulation model took place. It made it possible to more accurately forecast the nature of changes in water levels at gauging stations.

After loading the data into the hydrodynamic model, the calculation of the contours and depths of flooding was performed every hour for 24 hours ahead. Then services interpreting simulation results performed visualization of contours and depths of flooding.

The modeled contours of water objects and flooded zones, location of gauging stations (from which data is automatically loaded), graphs of changes in water levels at gauging stations, results of level change forecast are displayed in the system interface (Fig. 2-3). In addition, the system allows displaying the processed remote sensing data. During the testing, the following remote sensing data was used: images Resurs-P and Canopus-V (Russia), Sentinel-1 and Sentinel-2 (European Space Agency), and RADARSAT-2 (Canada). As part of this study, automatic processing of optical and radar data was carried out in order to identify flooded areas. In particular, during the spring flood of 2018, from April 1 to May 16, more than 20 satellite images were placed in the system. The use of remote sensing data allowed one not only to assess the quality of the simulation, but also to provide additional information on ice conditions, as well as unique data on specific phenomena caused by local conditions.

In addition to the operational mode, the scenario mode of operation was also tested during the experimental testing of the system: the simulation of the maximum contour of the flood zone, achieved during the catastrophic flood in 2016, was carried out. RADARSAT-2 data was applied for the analysis of flood in 2016. Processing was performed in accordance with the proposed approach using open source software: SNAP and QGIS. Pre-processing included radiometric calibration and speckle filtering. At the stage of thematic processing, the calculation of intensity thresholds for identifying water bodies with the construction of an open water and flooded areas mask was carried out. The post-processing included the automatic vectorization of raster data and visualization of the resulting vector layer containing flooded area in the system interface. The result of RADARSAT-2 data processing was compared with the results of the modeling (Fig. 4).
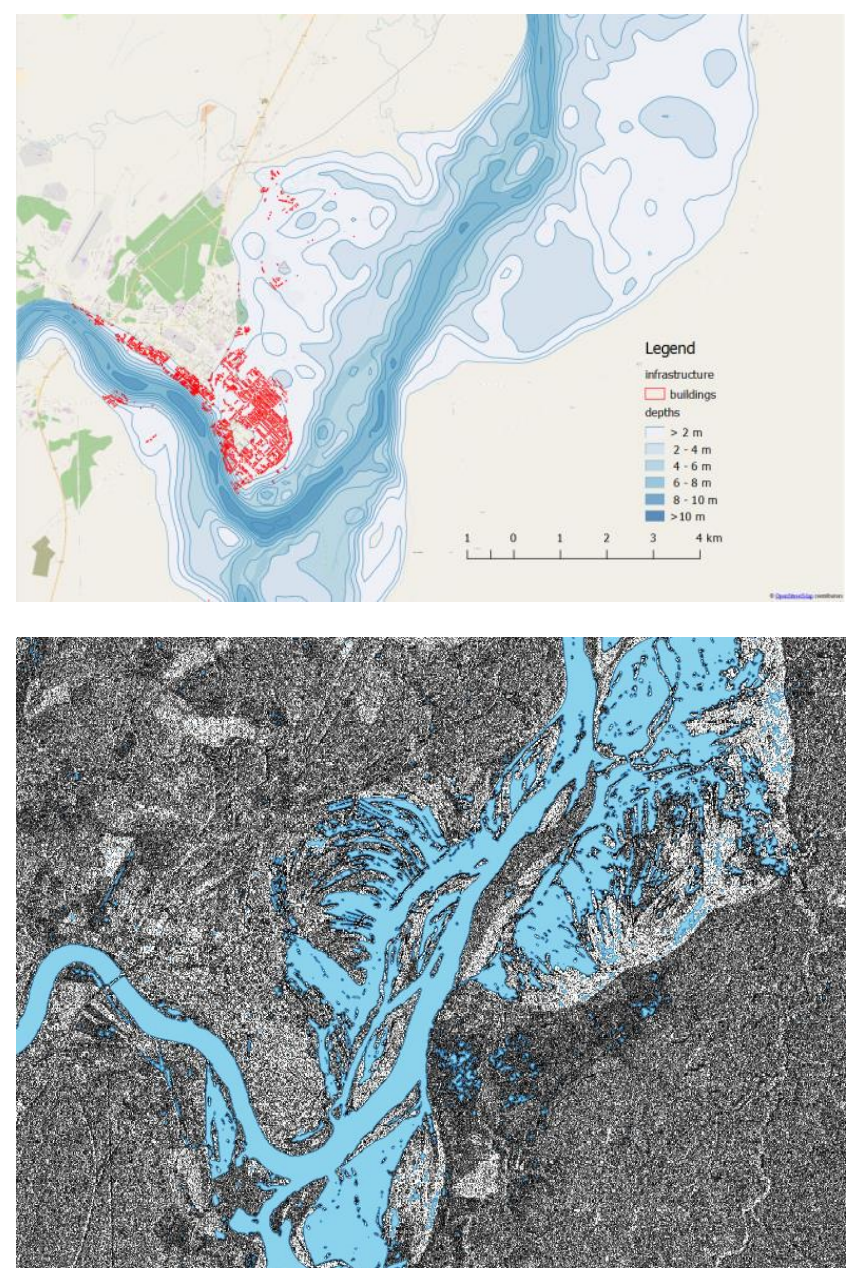

Figure 4. Comparison of simulation and remote sensing data processing results

Taking into account satellite data spatial resolution and errors arising from the use of the selected processing technology, it is possible to achieve a high overlap of processing results in open areas with a low level of urbanization. For the accurate detection, it is required that the open flooded area be at least 24 $\mathrm{m}^{2}$. In general, the discrepancy between the hydrodynamic model data and the results of remote sensing data processing the satellite image was $7 \%$. The maximum discrepancy between the simulated and observed water levels at the observation post in Velikiy Ustyug was $15 \mathrm{~cm}$. The forecast accuracy, assessed by the infrastructure objects in the flooded area, was at least $90 \%$. 
The developed system provides the following operations, which are important for the practical application:

- visualization of infrastructure objects in the flooded area according to the results of the forecast;

- preparation of reports on potential damage;

- automatic notification of citizens and organizations that own the defined objects.

\section{CONCLUSIONS}

The proposed approach of integrated use of GIS, remote sensing data and a set of models which was implemented on the basis of service- and event-oriented architectures has demonstrated its effectiveness in solving the problems of monitoring and operational flood forecasting. The results of system testing prove that such an approach fully meets the basic requirements for flood forecasting systems. The proposed system implementation based on an open software platform provides an easy access to the results of flood monitoring and forecasting. All the complexity associated with the use of heterogeneous geographically distributed information resources is hidden from the user due to the full automation of the computational process. This allows the system to be applied by all interested users including emergency services, authorities, commercial organizations and citizens. The further research is aimed at:

- development of modeling automation tools for identifying the locations of ice jams and their dynamics with a corresponding adjustment of the parameters of water distribution models;

- expansion of the set of hydrological and hydrodynamic models used for calculations.

\section{ACKNOWLEDGEMENTS}

The research described in this paper is supported by the Russian Science Foundation (project No. 17-11-01254).

\section{REFERENCES}

Agafonova S.A., Frolova N.L., Krylenko I.N. et al. Dangerous ice phenomena on the lowland rivers of European Russia // Natural Hazards. 2017. V. 88. № S1. P. 171-188. https://doi.org/10.1007/s11069-016-2580-x

Alabyan A.M., Lebedeva S.V. Flow dynamics in large tidal delta of the Nothern Dvina river: 2D simulation // $J$. Hydroinformatics. 2018. V. 20. № 4. P. 798-813. https://doi.org/10.2166/hydro.2018.051

Alabyan A. M., Zelentsov V. A., Krylenko I. N. et al. Development of Intelligent Information Systems for Operational River-Flood Forecasting // Herald of the Russian Academy of $\begin{array}{lllll}\text { Sciences. } & 2016 . & № & 1 . & \text { P.24-33. }\end{array}$ https://doi.org/10.1134/S1019331616010056

Aleksyuk A.I., Belikov V.V. STREAM 2D CUDA: software package for calculating currents, deformations of the bottom and transfer of contaminants in open streams using CUDA technology (on NVIDIA graphics processors). Certificate of State Registration of Computer Programs No. 2017660266. Russian Agency for Intellectual Property, 2017. [In Russian].

Arsene C., Al-Dabass D., Hartley J. Decision Support System for Water Distribution Systems Based on Neural Networks and Graphs // UKSim 14th International Conference on Computer Modelling and Simulation. 2012. 315-323.
Belikov V.V., Krylenko I.N., Alabyan A.M. et al. Twodimensional hydrodynamic flood modelling for populated valley areas of Russian rivers // Proc. IAHS. 2015. V. 370. 6974. https://doi.org/10.5194/piahs-370-69-2015

Borsch S., Burakov D., Zhabina I., Leont'eva E., Simonov Yu., Stepanov Yu., Khristoforov A., Yumina N.. A system for forecasting and early warning of the threat of flooding on the rivers of the Amur river basin // Scientific support for the implementation of the "Water Strategy of the Russian Federation for the period up to 2020" (2015), Karelian Research Center RAS Petrozavodsk. 6-12. [In Russian].

Bugayets A., Motovilov Yu., Belikov V., Gelfan A., Gonchukov L., Dod E., Kalugin A., Krylenko I., Moreydo V., Norin S., Rumyantsev A., Sazonov A.. Building an integrated hydrological modeling system using the OpenMI standard for flood risk management tasks by the example of the middle Amur river) // Scientific support for the implementation of the "Water Strategy of the Russian Federation for the period up to 2020" (2015), Karelian Research Center of RAS Petrozavodsk. 12-20. [In Russian].

Chini M., Hostache R., Giustarini L., Matgen P. A Hierarchical Split-Based Approach for Parametric Thresholding of SAR Images: Flood Inundation as a Test Case // IEEE Transactions on Geoscience and Remote Sensing. 2017, V. 55. № 12. 69756988.

Copernicus Emergency Management Service, European Flood Awareness System, 2019. https://www.efas.eu/ (17 July 2019).

Copernicus Emergency Management Service, Global Flood Awareness System, 2019. http://www.globalfloods.eu/ (17 July 2019).

Copernicus Emergency Management Service - Mapping, 2019. https://emergency.copernicus.eu/mapping/ems/emergencymanagement-service-mapping (17 July 2019).

Danish Hydrological Institute, 2019. Mike FLOOD. https://www.mikepoweredbydhi.com/ (17 July 2019).

Deltares, 2019. Flood forecasting system (Delft-FEWS) https://www.deltares.nl/en/software/flood-forecasting-systemdelft-fews-2/ (17 July 2019).

Deltares, Delft3D Development Team, 2019. Delft3D-FLOW. http://oss.deltares.nl/web/delft3d (17 July 2019).

European Space Agency, 2019. Thematic Exploitation Platform - Hydrology. https://hydrology-tep.eu/ (17 July 2019).

Jacobs, 2019. Flood Modeller. https://www.floodmodeller.com (17 July 2019).

He W., Xu L.D. Integration of Distributed Enterprise Applications: A Survey // IEEE Transactions on Industrial Informatics. 2014. V. 10. № 1. 35-42.

Hollan J.H. Adaptation in natural and artificial system. Cambridge, MA: MIT Press Cambridge, 1992. 
Hydrologic Engineering Center, 2019. HEC-RAS river analysis system. http://www.hec.usace.army.mil/software/hec-ras (17 July 2019).

Krylenko I., Motovilov Yu., Antokhina E. et al. Physicallybased distributed modelling of river runoff under changing climate conditions // Proc. IAHS. 2015. V. 368. 156-161. https://doi.org/10.5194/piahs-368-156-2015

Lantrip J., Griffin M., Aly A. Results of near-term forecasting of surface water supplies // World Water Congress 2005: Impacts of Global Climate Change. Proceedings of the 2005 World Water and Environmental Resources Congress. Anchorage, Alaska, US, 2005. 436.

Martinis S., Rieke C. Backscatter Analysis Using MultiTemporal and Multi-Frequency SAR Data in the Context of Flood Mapping at River Saale, Germany // Remote Sens. 2015. № $7.7732-7752$.

Motovilov Yu.. Certificate of state registration in Rospatent No 2013610703. ECOMAG. Russia, 2013. [In Russian].

NOAA National Water Center, 2019. National Water Model. http://water.noaa.gov/about/nwm (17 July 2019).

Paik H., Lemos A., Barukh M. et al. Web Service Implementation and Composition Techniques. Springer International Publishing, 2017.

Ponomarenko M. R., Pimanov I. Y. Implementation of Synthetic Aperture Radar and Geoinformation Technologies in the Complex Monitoring and Managing of the Mining Industry Objects // Cybernetics and Mathematics Applications in Intelligent Systems. CSOC 2017. Advances in Intelligent Systems and Computing. Springer, Cham. 2017. V. 574. https://doi.org/10.1007/978-3-319-57264-2_30

Refice A., D'Addabbo A., Capolongo D. (eds) Flood Monitoring through Remote Sensing. Springer Remote Sensing. Photogrammetry. Springer, Cham. 2017.

Sokolov B.V., Zelentsov V.A., Brovkina O., Mochalov V.F., Potryasaev S.A. Models adaptation of complex objects structure dynamics control // Intelligent Systems in Cybernetics and Automation Theory. CSOC 2015. Advances in Intelligent Systems and Computing, 2015, vol 348. Springer, Cham. https://doi.org/10.1007/978-3-319-18503-3_3

Ting-Huan K., Chi-Hua C., Hsu-Yang K. Applications of the web service middleware framework based on the BPEL // Proceedings of the IEEE 5th Global Conference on Consumer Electronics, 2016, 1-5.

University of Bristol, School of Geographical Sciences, Hydrology Group, 2019. LISPFLOOD-FP. http://www.bristol.ac.uk/geography/research/hydrology/models/ lisflood (17 July 2019).

Wang Y. A formal model of QoS-aware web service orchestration engine // IEEE Transactions on Network and Service Management. 2016. V. 13. № 1. 113-125.

Zelentsov V.A., Kovalev A.P., Pimanov I.Yu. Hierarchical control system for territory management using heterogeneous spatial data // Izv. vuzov. Priborostroenie. 2016. Vol. 59, N 11,
944-951 [In Russian]. https://doi.org/10.17586/0021-34542016-59-11-944-951

Zelentsov V.A., Potryasaev S.A. Architecture and examples of the implementation of the information platform for the creation and provision of thematic services using the Earth remote sensing data // Proceedings of SPIIRAS. 2017. Vol. 6 (55), pp. 86-113 [In Russian]. https://doi.org/10.15622/sp.55.4

Zelentsov, V.A., Potryasaev, S.A., Pimanov, I.J., Nemykin, S.A. Creation of intelligent information flood forecasting systems based on service oriented architecture // Advances in Intelligent Systems and Computing, vol. 466, Springer International Publishing Switzerland 2016, 371-381. https://doi.org/10.1007/978-3-319-33389-2_35 